\title{
Konsep Fungsi Semikontinu
}

\author{
Malahayati
}

Program Studi Matematika, Fakultas Sains dan Teknologi, UIN Sunan Kalijaga, Jl. Marsda Adisucipto No. 1 Yogyakarta, Indonesia

Korespondensi; Email: malahayati_01@yahoo.co.id

\begin{abstract}
Abstrak
Makalah ini membahas konsep dasar dan beberapa fungsi semicontinuous, dimulai dengan mengenalkan konsep upper limit dan lower limit.
\end{abstract}

Kata Kunci: Batas bawah; Fungsi semikontinu; Batas atas

\begin{abstract}
This paper discusses the basic concepts and some of the semicontinuous functions, begins by introducing the concept of upper limit and lower limit.
\end{abstract}

Keywords: Lower limit; Semicontinuous function; Upper limit

\section{Pendahuluan}

Konsep fungsi semikontinu didefinisikan dengan memanfaatkan pengertian limit atas dan limit bawah, atau yang biasa dikenal dengan limit superior dan limit inferior. Konsep fungsi semikontinu banyak dimanfaatkan oleh peneliti diantaranya dalam mendefinisikan ruang Baire-1 dan subruang lainnya.

Pada paper ini fungsi fungsi yang dibicarakan bernilai real dan didefinisikan pada $E$, dengan $E$ himpunan bagian dari ruang metrik $X$. Sebelumnya disepakati terlebih dahulu bahwa setiap pengambilan infimum dan supremum dari suatu himpunan pada paper ini, himpunan yang dimaksud merupakan himpunan bagian dari $\overline{\boldsymbol{R}}$ (real extended) dengan $\overline{\boldsymbol{R}}=\boldsymbol{R} \cup\{-\infty, \infty\}$.

Dalam mendefinisikan fungsi semikontinu diperlukan konsep limit atas dan limit bawah, oleh karena itu, berikut dimulai dengan menjelaskan konsep limit atas dan limit bawah beserta sifat-sifatnya.

Definisi 1.1. Diberikan fungsi $f$ yang didefinisikan pada $E$ dan $x_{0} \in E$.

1) Limit atas (upper limit) fungsi $f$ ketika $x$ mendekati $x_{0}$ ditulis dengan $\varlimsup_{x \rightarrow x_{0}} f(x)$ dan didefinisikan

$$
\varlimsup_{x \rightarrow x_{0}} f(x)=\inf \left\{M_{\varepsilon}\left(f, x_{0}\right): \varepsilon>0\right\}
$$

dengan $M_{\varepsilon}\left(f, x_{0}\right)=\sup \left\{f(x): x \in N_{\varepsilon}\left(x_{0}\right) \cap E\right\}$.

2) Limit bawah (lower limit) fungsi $f$ ketika $x$ mendekati $x_{0}$ ditulis dengan $\underline{\lim }_{x \rightarrow x_{0}} f(x)$ dan didefinisikan

$$
\underline{\lim }_{x \rightarrow x_{0}} f(x)=\sup \left\{m_{\varepsilon}\left(f, x_{0}\right): \varepsilon>0\right\},
$$

dengan $m_{\varepsilon}\left(f, x_{0}\right)=\inf \left\{f(x): x \in N_{\varepsilon}\left(x_{0}\right) \cap E\right\}$.

Pada Definisi 1.1 diatas, nilai limitnya selalu ada dan dapat bernilai berhingga, $+\infty$, atau $-\infty$. Selanjutnya akan dibahas sifat-sifat yang terkait dengan limit atas dan limit bawah. 
Lemma 1.2. Diberikan fungsi $f$ yang didefinisikan pada $E$ dan $x_{0} \in E$.

1) Jika $h>\varlimsup_{x \rightarrow x_{0}} f(x)$, maka terdapat $\varepsilon>0$ sehingga untuk setiap $0<\alpha \leq \varepsilon$ berlaku

$$
\varlimsup_{x \rightarrow x_{0}} f(x) \leq M_{\alpha}\left(f, x_{0}\right) \leq M_{\varepsilon}\left(f, x_{0}\right)<h
$$

2) Jika $h<\underline{\lim }_{x \rightarrow x_{0}} f(x)$, maka terdapat $\varepsilon>0$ sehingga untuk setiap $0<\delta \leq \varepsilon$ berlaku

$$
\varliminf_{x \rightarrow x_{0}} f(x) \geq m_{\delta}\left(f, x_{0}\right) \geq m_{\varepsilon}\left(f, x_{0}\right)>h .
$$

3) Jika $h<M_{\varepsilon}\left(f, x_{0}\right)$ maka terdapat $x \in N_{\varepsilon}\left(x_{0}\right) \cap E$ sehingga berlaku $h<f(x) \leq M_{\varepsilon}\left(f, x_{0}\right)$.

4) Jika $h>m_{\varepsilon}\left(f, x_{0}\right)$ maka terdapat $x \in N_{\varepsilon}\left(x_{0}\right) \cap E$ sehingga berlaku $m_{\varepsilon}\left(f, x_{0}\right) \leq f(x)<h$.

Bukti: Cukup dibuktikan bagian (1) dan (2), untuk bagian (3) dan (4) bukti dilakukan dengan cara serupa.

1) Diketahui $h>\varlimsup_{x \rightarrow x_{0}} f(x)=\inf \left\{M_{\varepsilon}\left(f, x_{0}\right): \varepsilon>0\right\}$, berarti terdapat $\varepsilon>0$ sehingga $M_{\varepsilon}\left(f, x_{0}\right)<h$.

Selanjutnya untuk sebarang $\alpha$, dengan $0<\alpha \leq \varepsilon$ diperoleh $N_{\alpha}\left(x_{0}\right) \cap E \subseteq N_{\varepsilon}\left(x_{0}\right) \cap E$. Oleh karena itu, diperoleh

$$
\sup \left\{f(x): x \in N_{\alpha}\left(x_{0}\right) \cap E\right\} \leq \sup \left\{f(x): x \in N_{\varepsilon}\left(x_{0}\right) \cap E\right\}
$$

Akibatnya, $M_{\alpha}\left(f, x_{0}\right) \leq M_{\varepsilon}\left(f, x_{0}\right)$. Dengan kata lain diperoleh

$$
\varlimsup_{x \rightarrow x_{0}} f(x) \leq M_{\alpha}\left(f, x_{0}\right) \leq M_{\varepsilon}\left(f, x_{0}\right)<h .
$$

2) Diketahui $h<\lim _{x \rightarrow x_{0}} f(x)=\sup \left\{m_{\varepsilon}\left(f, x_{0}\right): \varepsilon>0\right\}$, berarti terdapat $\varepsilon>0$ sehingga $m_{\varepsilon}\left(f, x_{0}\right)>h$. Selanjutnya untuk sebarang $\delta$, dengan $0<\delta \leq \varepsilon$ diperoleh $N_{\delta}\left(x_{0}\right) \cap E \subseteq N_{\varepsilon}\left(x_{0}\right) \cap E$. Oleh karena itu, diperoleh

$$
\inf \left\{f(x): x \in N_{\delta}\left(x_{0}\right) \cap E\right\} \geq \inf \left\{f(x): x \in N_{\varepsilon}\left(x_{0}\right) \cap E\right\} .
$$

Akibatnya, $m_{\delta}\left(f, x_{0}\right) \geq m_{\varepsilon}\left(f, x_{0}\right)$. Dengan kata lain diperoleh

$$
\underline{\lim }_{x \rightarrow x_{0}} f(x) \geq m_{\delta}\left(f, x_{0}\right) \geq m_{\varepsilon}\left(f, x_{0}\right)>h .
$$

Lemma 1.3. Diberikan fungsi $f$ yang didefinisikan pada $E$ dan $x_{0} \in E$. Jika $-\infty<c<0$ maka berlaku

1) $\underline{\lim }_{x \rightarrow x_{0}} c f(x)=c \varlimsup_{x \rightarrow x_{0}} f(x)$

2) $\varlimsup_{x \rightarrow x_{0}} c f(x)=c \overline{\lim }_{x \rightarrow x_{0}} f(x)$.

Selanjutnya, jika $0 \leq c<\infty$ maka berlaku

1) $\varlimsup_{x \rightarrow x_{0}} c f(x)=c \varlimsup_{x \rightarrow x_{0}} f(x)$

2) $\underline{\lim }_{x \rightarrow x_{0}} c f(x)=c \underline{\lim }_{x \rightarrow x_{0}} f(x)$. 
Bukti: Untuk $-\infty<c<0$, diperoleh

1) Diambil $\varepsilon>0$ sebarang, maka diperoleh

$$
\begin{aligned}
m_{\varepsilon}\left(c f, x_{0}\right) & =\inf \left\{c f(x): x \in N_{\varepsilon}\left(x_{0}\right) \cap E\right\} \\
& =c \sup \left\{f(x): x \in N_{\varepsilon}\left(x_{0}\right) \cap E\right\} \\
& =c M_{\varepsilon}\left(f, x_{0}\right) .
\end{aligned}
$$

Oleh karena itu, diperoleh

$$
\begin{aligned}
\underline{\lim }_{x \rightarrow x_{0}} c f(x)= & \sup \left\{m_{\varepsilon}\left(c f, x_{0}\right): \varepsilon>0\right\} \\
& =\sup \left\{c M_{\varepsilon}\left(f, x_{0}\right): \varepsilon>0\right\} \\
& =c \inf \left\{M_{\varepsilon}\left(f, x_{0}\right): \varepsilon>0\right\} \\
& =c \varlimsup_{x \rightarrow x_{0}} f(x) .
\end{aligned}
$$

2) $\varlimsup_{x \rightarrow x_{0}} c f(x)=c \cdot \frac{1}{c} \cdot \varlimsup_{x \rightarrow x_{0}} c f(x)=c \cdot \overline{\lim }_{x \rightarrow x_{0}} c \cdot \frac{1}{c} f(x)=c \underline{\underline{\lim }}_{x \rightarrow x_{0}} f(x)$.

Selanjutnya, untuk $0 \leq c<\infty$, diperoleh

3) $\varlimsup_{x \rightarrow x_{0}} c f(x)=\varlimsup_{x \rightarrow x_{0}}(-1)(-c) f(x)=(-1) \underline{\lim }_{x \rightarrow x_{0}}(-c) f(x)$

$$
=(-1)(-c) \varlimsup_{x \rightarrow x_{0}} f(x)=c \varlimsup_{x \rightarrow x_{0}} f(x) \text {. }
$$

4) $\underline{\lim }_{x \rightarrow x_{0}} c f(x)=\underline{\lim }_{x \rightarrow x_{0}}(-1)(-c) f(x)=(-1) \varlimsup_{x \rightarrow x_{0}}(-c) f(x)$

$$
=(-1)(-c) \underline{\lim }_{x \rightarrow x_{0}} f(x)=c \underline{\lim }_{x \rightarrow x_{0}} f(x) \text {. }
$$

Sebelum membahas sifat-sifat limit atas dan limit bawah lebih lanjut, berikut ini akan didefinisikan terlebih dahulu beberapa pengertian agar mudah dalam memahami pembuktian sifat-sifat selanjutnya.

Persekitaran di $\infty$ dengan jari-jari $\varepsilon>0$ sembarang, ditulis $N_{\varepsilon}(\infty)$ dan didefinisikan

$$
N_{\varepsilon}(\infty)=\left\{x: x>\frac{1}{\varepsilon}\right\}
$$

Sedangkan persekitaran di $-\infty$ dengan jari-jari $\varepsilon>0$ sembarang, ditulis $N_{\varepsilon}(-\infty)$ dan didefinisikan

$$
N_{\varepsilon}(-\infty)=\left\{x: x<-\frac{1}{\varepsilon}\right\} .
$$

Selanjutnya, diberikan barisan bilangan $\left\{x_{n}\right\}$. Barisan $\left\{x_{n}\right\}$ dikatakan konvergen apabila terdapat bilangan $k$ sehingga untuk $\varepsilon>0$ sembarang, terdapat $n_{\varepsilon}>0$ akibatnya untuk setiap $n>n_{\varepsilon}$ berlaku $x_{n} \in N_{\varepsilon}(k)$.

Teorema 1.4. Diberikan fungsi $f$ yang didefinisikan pada $E$ dan $x_{0} \in E$.

1) Jika $h=\varlimsup_{x \rightarrow x_{0}} f(x)$ atau $h=\lim _{x \rightarrow x_{0}} f(x)$ maka terdapat barisan $\left\{x_{n}\right\}$ di $E$ sehingga $\left\{x_{n}\right\}$ konvergen ke $x_{0}$ dan $\lim _{n \rightarrow \infty} f\left(x_{n}\right)=h$.

2) Jika $h>\varlimsup_{x \rightarrow x_{0}} f(x)$ atau $h<\underline{\lim }_{x \rightarrow x_{0}} f(x)$ maka tidak ada barisan $\left\{x_{n}\right\}$ di $E$ sehingga $\left\{x_{n}\right\}$ konvergen ke $x_{0}$ dan $\lim _{n \rightarrow \infty} f\left(x_{n}\right)=h$. 


\section{Bukti:}

1) Misalkan $h=\varlimsup_{x \rightarrow x_{0}} f(x)$. Diambil sembarang $x_{0} \in E$. Apabila $x_{0} \in E \backslash E^{\prime}$, maka diperoleh

$$
h=\varlimsup_{x \rightarrow x_{0}} f(x)=\inf \left\{M_{\varepsilon}\left(f, x_{0}\right): \varepsilon>0\right\}=f\left(x_{0}\right)
$$

Oleh karena itu, terdapat barisan $\left\{x_{n}\right\}$ di $E$ dengan $x_{n}=x_{0}$ untuk setiap $n \in \boldsymbol{N}$, sehingga $\left\{x_{n}\right\}$ konvergen ke $x_{0}$ dan $\lim _{n \rightarrow \infty} f\left(x_{n}\right)=f\left(x_{0}\right)=h$. Selanjutnya, ditinjau untuk $x_{0} \in E \cap E^{\prime}$. Diambil sembarang $n \in N$. Akan ditunjukkan terlebih dahulu bahwa terdapat $\alpha>0$ dengan $\alpha \leq \frac{1}{n}$ sehingga $M_{\alpha}\left(f, x_{0}\right) \in N_{\frac{1}{n}}(h)$.

Apabila $h=\infty$, maka terdapat $\alpha>0$ dengan $\alpha \leq \frac{1}{n}$ sehingga berlaku $M_{\alpha}\left(f, x_{0}\right) \geq$ $\varlimsup_{x \rightarrow x_{0}} f(x)=h=\infty$. Dengan demikian diperoleh $M_{\alpha}\left(f, x_{0}\right)=\infty$ dan jelas $M_{\alpha}\left(f, x_{0}\right) \in N_{\frac{1}{n}}(\infty)$.

Apabila $h<\infty$, maka $N_{\frac{1}{n}}(h)$ memuat bilangan $k$ sehingga $k>h=\varlimsup_{x \rightarrow x_{0}} f(x)$. berdasarkan Lemma 1.2 bagian (1), terdapat $\varepsilon>0$ sehingga untuk setiap $0<\beta \leq \varepsilon$ berlaku

$$
h \leq M_{\beta}\left(f, x_{0}\right) \leq M_{\varepsilon}\left(f, x_{0}\right)<k .
$$

Dipilih $\alpha=\min \left\{\frac{1}{n}, \varepsilon\right\}$, sehingga diperoleh $h \leq M_{\alpha}\left(f, x_{0}\right)<k$. Akibatnya $M_{\alpha}\left(f, x_{0}\right) \in N_{\frac{1}{n}}(h)$. Dengan demikian terbukti bahwa terdapat $\alpha>0$ dengan $\alpha \leq \frac{1}{n}$ sehingga $M_{\alpha}\left(f, x_{0}\right) \in N_{\frac{1}{n}}(h)$. Selanjutnya akan ditunjukkan terdapat $x_{n} \in N_{\alpha}\left(x_{0}\right) \cap E$ sehingga berlaku $f\left(x_{n}\right) \in N_{\frac{1}{n}}\left(M_{\alpha}\left(f, x_{0}\right)\right)$.

Apabila $M_{\alpha}\left(f, x_{0}\right)>-\infty$ maka terdapat bilangan $k$ sehingga $-\infty<k<M_{\alpha}\left(f, x_{0}\right)$ dan $k \in$ $N_{\frac{1}{n}}\left(M_{\alpha}\left(f, x_{0}\right)\right)$. Berdasarkan Lemma 1.2 bagian (3), terdapat $x_{n} \in N_{\alpha}\left(x_{0}\right) \cap E$ sehingga $k<$ $f\left(x_{n}\right) \leq M_{\alpha}\left(f, x_{0}\right)$. Dengan kata lain diperoleh $f\left(x_{n}\right) \in N_{\frac{1}{n}}\left(M_{\alpha}\left(f, x_{0}\right)\right)$.

Jadi untuk setiap $n \in N$ terdapat $0<\alpha \leq \frac{1}{n}$ sehingga terdapat $x_{n} \in N_{\alpha}\left(x_{0}\right) \cap E$. Dengan kata lain, terdapat barisan $\left\{x_{n}\right\}$ sehingga barisan $\left\{x_{n}\right\}$ konvergen ke $x_{0}$.

Selanjutnya, karena untuk setiap $n \in N, f\left(x_{n}\right) \in N_{\frac{1}{n}}\left(M_{\alpha}\left(f, x_{0}\right)\right)$ dan $M_{\alpha}\left(f, x_{0}\right) \in N_{\frac{1}{n}}(h)$ maka diperoleh $f\left(x_{n}\right) \in N_{\frac{2}{n}}(h)$ untuk $n \geq 2$. Dengan kata lain $f\left(x_{n}\right) \rightarrow h$. Untuk kasus $h=\underline{\lim }_{x \rightarrow x_{0}} f(x)$ dapat dibuktikan dengan cara yang sama.

2) Misalkan $h>\varlimsup_{x \rightarrow x_{0}} f(x)$. Diambil sembarang $x_{0} \in E$. Apabila $x_{0} \in E \backslash E^{\prime}$, maka diperoleh

$$
h>\varlimsup_{x \rightarrow x_{0}} f(x)=f\left(x_{0}\right) .
$$

Andaikan ada barisan $\left\{x_{n}\right\}$ di $E$ sehingga $\left\{x_{n}\right\}$ konvergen ke $x_{0}$ dan $\lim _{n \rightarrow \infty} f\left(x_{n}\right)=h$. Dengan demikian, barisan yang konvergen ke $x_{0}$ hanya barisan $\left\{x_{n}\right\}$ dengan $x_{n}=x_{0}$ untuk setiap $n$. Oleh karena itu diperoleh $\lim _{n \rightarrow \infty} f\left(x_{n}\right)=f\left(x_{0}\right)<h$. Kontradiksi dengan $\lim _{n \rightarrow \infty} f\left(x_{n}\right)=h$. Berarti tidak ada barisan $\left\{x_{n}\right\}$ di $E$ dengan $\left\{x_{n}\right\}$ konvergen ke $x_{0}$ dan $\lim _{n \rightarrow \infty} f\left(x_{n}\right)=h$. Selanjutnya, ditinjau untuk $x_{0} \in E \cap E^{\prime}$. Andaikan ada barisan $\left\{x_{n}\right\}$ di $E$ sehingga $\left\{x_{n}\right\}$ konvergen ke $x_{0}$ dan $\lim _{n \rightarrow \infty} f\left(x_{n}\right)=h$. Karena $h>\varlimsup_{x \rightarrow x_{0}} f(x)$ maka ada bilangan $k$ sehingga 


$$
h>k>\varlimsup_{x \rightarrow x_{0}} f(x)
$$

Karena $\lim _{n \rightarrow \infty} f\left(x_{n}\right)=h>k$ maka terdapat $N \in \boldsymbol{N}$ sehingga $f\left(x_{n}\right)>k$ untuk setiap $n \geq N$. Oleh karena itu, untuk sembarang $\varepsilon>0, N_{\varepsilon}\left(x_{0}\right) \cap E$ memuat tak hingga banyak titik-titik $x_{n}$ di $E$ sehingga $f\left(x_{n}\right)>k$. Berarti untuk sembarang $\varepsilon>0$, diperoleh

$$
M_{\varepsilon}\left(f, x_{0}\right)=\sup \left\{f(x): x \in N_{\varepsilon}\left(x_{0}\right) \cap E\right\}>k \text {. }
$$

Sehingga berlaku $\varlimsup_{x \rightarrow x_{0}} f(x) \geq k$. Kontradiksi dengan pernyataan (1.1). Jadi tidak ada barisan $\left\{x_{n}\right\}$ di $E$ dengan $\left\{x_{n}\right\}$ konvergen ke $x_{0}$ dan $\lim _{n \rightarrow \infty} f\left(x_{n}\right)=h$. Untuk kasus $h<{\underline{x \rightarrow x_{0}}}_{x \rightarrow} f(x)$ dapat dibuktikan dengan cara yang sama.

Selanjutnya diberikan suatu akibat dari Teorema 1.4, yang menyatakan bahwa nilai limit bawah dari sembarang fungsi lebih kecil atau sama dengan nilai limit atasnya.

Akibat 1.5. Diberikan fungsi $f$ yang didefinisikan pada $E$ dan $x_{0} \in E$ maka berlaku

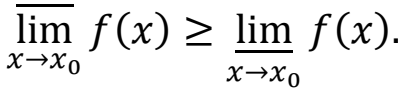

Bukti: Namakan $h=\varlimsup_{x \rightarrow x_{0}} f(x)$, maka berdasarkan Teorema 1.4 bagian (1) terdapat barisan $\left\{x_{n}\right\}$ di $E$ dengan sifat $x_{n} \rightarrow x_{0}$ sehingga $f\left(x_{n}\right) \rightarrow h$.

Akan dibuktikan $h \geq \underline{\lim }_{x \rightarrow x_{0}} f(x)$. Andaikan $h<\underline{\lim }_{x \rightarrow x_{0}} f(x)$, maka berdasarkan Teorema 1.4 bagian (2), tidak ada barisan $\left\{x_{n}\right\}$ di $E$ sehingga $x_{n} \rightarrow x_{0}$ dan $f\left(x_{n}\right) \rightarrow h$. Kontradiksi dengan pernyataan (1.2). Jadi terbukti $\varlimsup_{x \rightarrow x_{0}} f(x) \geq \lim _{x \rightarrow x_{0}} f(x)$.

Teorema berikut menyatakan hubungan limit atas dan limit bawah. Apabila diperoleh nilai limit atas dan limit bawah sama maka dikatakan nilai limitnya ada.

Teorema 1.6. Diberikan fungsi $f$ yang didefinisikan pada $E$ dan $x_{0}$ titik limit $E$. Jika $\varlimsup_{x \rightarrow x_{0}} f(x)=\underline{\lim }_{x \rightarrow x_{0}} f(x)=k$ maka $\lim _{x \rightarrow x_{0}} f(x)=k$.

Bukti: Diketahui $\varlimsup_{x \rightarrow x_{0}} f(x)=\underline{\lim }_{x \rightarrow x_{0}} f(x)=k$. Diambil $\varepsilon>0$ sembarang. Berdasarkan Lemma 1.2 terdapat $\alpha, \beta>0$ sehingga berlaku

$$
k-\varepsilon<m_{\alpha}\left(f, x_{0}\right) \leq k \leq M_{\beta}\left(f, x_{0}\right)<k+\varepsilon .
$$

Selanjutnya dipilih $0<\gamma<\min \{\alpha, \beta\}$, sehingga diperoleh

$$
k-\varepsilon<m_{\alpha}\left(f, x_{0}\right) \leq m_{\gamma}\left(f, x_{0}\right) \leq k \leq M_{\gamma}\left(f, x_{0}\right) \leq M_{\beta}\left(f, x_{0}\right)<k+\varepsilon .
$$

Oleh karena itu, diperoleh

$$
k-\varepsilon<m_{\gamma}\left(f, x_{0}\right) \leq M_{\gamma}\left(f, x_{0}\right)<k+\varepsilon .
$$

Jadi, untuk sembarang $\varepsilon>0$ terdapat $\gamma>0$, sehingga apabila $x \in N_{\gamma}\left(x_{0}\right) \cap E$ berlaku $f(x) \in N_{\varepsilon}(k)$. Dengan kata lain diperoleh $\lim _{x \rightarrow x_{0}} f(x)=k$. 
Lemma 1.7. Diberikan fungsi $f$ yang didefinisikan pada $(a, b)$, dengan $-\infty \leq a<b \leq \infty$.

1) Jika fungsi $f$ naik monoton pada $(a, b)$ maka

$\lim _{x \rightarrow a} f(x)=\inf \{f(x): x \in(a, b)\}$.

2) Jika fungsi $f$ turun monoton pada $(a, b)$ maka

$\lim _{x \rightarrow a} f(x)=\sup \{f(x): x \in(a, b)\}$.

Menggunakan Lemma 1.7 dapat ditunjukkan teorema berikut ini.

Teorema 1.8. Diberikan fungsi $f$ yang didefinisikan pada $E$ dan $x_{0} \in E$, maka berlaku

1) $\varlimsup_{x \rightarrow x_{0}} f(x)=\inf \left\{M_{\varepsilon}\left(f, x_{0}\right): \varepsilon>0\right\}=\lim _{\varepsilon \rightarrow 0} M_{\varepsilon}\left(f, x_{0}\right)$

2) $\varliminf_{x \rightarrow x_{0}} f(x)=\sup \left\{m_{\varepsilon}\left(f, x_{0}\right): \varepsilon>0\right\}=\lim _{\varepsilon \rightarrow 0} m_{\varepsilon}\left(f, x_{0}\right)$.

Bukti: Diberikan $\varepsilon_{1}, \varepsilon_{2}>0$ sembarang, dengan $\varepsilon_{1}<\varepsilon_{2}$ maka diperoleh $M_{\varepsilon_{1}}\left(f, x_{0}\right) \leq M_{\varepsilon_{2}}\left(f, x_{0}\right)$ dan $m_{\varepsilon_{1}}\left(f, x_{0}\right) \geq m_{\varepsilon_{2}}\left(f, x_{0}\right)$. Dengan kata lain, fungsi $g(\varepsilon)=M_{\varepsilon}\left(f, x_{0}\right)$ naik monoton pada $(0, \infty)$ dan fungsi $h(\varepsilon)=m_{\varepsilon}\left(f, x_{0}\right)$ turun monoton pada $(0, \infty)$. Berdasarkan Lemma 1.7 diperoleh

1) $\lim _{\varepsilon \rightarrow 0} M_{\varepsilon}\left(f, x_{0}\right)=\lim _{\varepsilon \rightarrow 0} g(\varepsilon)=\inf \{g(\varepsilon): 0<\varepsilon<\infty\}$

$$
\begin{aligned}
& =\inf \left\{M_{\varepsilon}\left(f, x_{0}\right): 0<\varepsilon<\infty\right\} \\
& =\varlimsup_{x \rightarrow x_{0}} f(x) .
\end{aligned}
$$

2) $\lim _{\varepsilon \rightarrow 0} m_{\varepsilon}\left(f, x_{0}\right)=\lim _{\varepsilon \rightarrow 0} h(\varepsilon)=\sup \{h(\varepsilon): 0<\varepsilon<\infty\}$

$$
\begin{aligned}
& =\sup _{\varepsilon}\left\{m_{\varepsilon}\left(f, x_{0}\right): 0<\varepsilon<\infty\right\} \\
& =\varliminf_{x \rightarrow x_{0}} f(x) .
\end{aligned}
$$

Teorema 1.9. Diberikan fungsi-fungsi $f, g$ dan $f+g$ yang didefinisikan pada $E$ dan $x_{0} \in E$, maka berlaku

1) $\varlimsup_{x \rightarrow x_{0}}(f(x)+g(x)) \leq \varlimsup_{x \rightarrow x_{0}} f(x)+\varlimsup_{x \rightarrow x_{0}} g(x)$.

2) $\underline{\lim }_{x \rightarrow x_{0}}(f(x)+g(x)) \geq \underline{\lim }_{x \rightarrow x_{0}} f(x)+\underline{\lim }_{x \rightarrow x_{0}} g(x)$.

\section{Fungsi Semikontinu}

Fungsi semikontinu erat kaitannya dengan fungsi kontinu, oleh sebab itu berikut diberikan terlebih dahulu pengertian fungsi kontinu.

Definisi 2.1. Diberikan ruang metrik $(X, d)$ dan fungsi $f$ yang didefinisikan pada $X$. Fungsi $f$ dikatakan kontinu di $x_{0} \in X$ jika untuk setiap bilangan $\varepsilon>0$ terdapat $\delta>0$ sehingga untuk setiap $x \in X$ dengan $d\left(x, x_{0}\right)<\delta$ berlaku $f(x) \in N_{\varepsilon}\left(f\left(x_{0}\right)\right)$. Selanjutnya, $f$ dikatakan kontinu pada $X$ jika $f$ kontinu disetiap titik $x \in X$.

Setelah diperkenalkan konsep limit atas dan limit bawah, berikut diberikan definisi fungsi semikontinu. Definisi 2.2. Diberikan fungsi $f$ yang didefinisikan pada $E$ dan $x_{0} \in E$.

1) Fungsi $f$ dikatakan semikontinu atas (upper semicontinuous) di $x_{0}$ apabila $f\left(x_{0}\right)=\varlimsup_{x \rightarrow x_{0}} f(x)$.

Selanjutnya, fungsi $f$ dikatakan semikontinu atas pada $E$ apabila fungsi $f$ semikontinu atas disetiap $x_{0} \in E$. 
2) Fungsi $f$ dikatakan semikontinu bawah (lower semicontinuous) di $x_{0}$ apabila $f\left(x_{0}\right)=\varliminf_{x \rightarrow x_{0}} f(x)$. Selanjutnya, fungsi $f$ dikatakan semikontinu bawah pada $E$ apabila fungsi $f$ semikontinu bawah disetiap $x_{0} \in E$.

3) Fungsi yang semikontinu atas atau semikontinu bawah dinamakan fungsi semikontinu.

Teorema 2.3. Diberikan fungsi $f$ yang didefinisikan pada $E$. Fungsi $f$ kontinu pada $E$ jika dan hanya jika fungsi $f$ semikontinu atas dan semikontinu bawah pada $E$.

Bukti: Diambil sembarang $x_{0} \in E$. Apabila $x_{0} \in E \backslash E^{\prime}$ maka berdasarkan Definisi 1.6 dan Definisi 2.2 jelas pernyataan berlaku. Selanjutnya, ditinjau untuk $x_{0} \in E \cap E^{\prime}$.

(Syarat perlu). Diketahui fungsi $f$ kontinu pada $E$, maka fungsi $f$ kontinu di $x_{0}$, berarti berlaku $f\left(x_{0}\right)=\lim _{x \rightarrow x_{0}} f(x)$. Untuk sembarang $\varepsilon>0$ berlaku

$$
M_{\varepsilon}\left(f, x_{0}\right)=\sup \left\{f(x): x \in N_{\varepsilon}\left(x_{0}\right) \cap E\right\} \geq f\left(x_{0}\right) .
$$

Oleh karena itu diperoleh

$$
\varlimsup_{x \rightarrow x_{0}} f(x)=\inf \left\{M_{\varepsilon}\left(f, x_{0}\right): \varepsilon>0\right\} \geq f\left(x_{0}\right) .
$$

Selanjutnya, diambil sembarang $\gamma>0$. Karena $f\left(x_{0}\right)=\lim _{x \rightarrow x_{0}} f(x)$ maka terdapat $\varepsilon>0$ sehingga untuk setiap $x \in N_{\varepsilon}\left(x_{0}\right) \cap E$ berlaku $f(x)<f\left(x_{0}\right)+\frac{\gamma}{2}$. Akibatnya, diperoleh

$$
M_{\varepsilon}\left(f, x_{0}\right)=\sup \left\{f(x): x \in N_{\varepsilon}\left(x_{0}\right) \cap E\right\} \leq f\left(x_{0}\right)+\frac{\gamma}{2}<f\left(x_{0}\right)+\gamma \text {. }
$$

Oleh karena itu diperoleh

$$
\varlimsup_{x \rightarrow x_{0}} f(x)=\inf \left\{M_{\varepsilon}\left(f, x_{0}\right): \varepsilon>0\right\} \leq M_{\varepsilon}\left(f, x_{0}\right)<f\left(x_{0}\right)+\gamma,
$$

untuk sembarang $\gamma>0$. Karena untuk $\gamma>0$ sembarang selalu berlaku $0 \leq \varlimsup_{x \rightarrow x_{0}} f(x)-f\left(x_{0}\right)<\gamma$, maka diperoleh $\varlimsup_{x \rightarrow x_{0}} f(x)=f\left(x_{0}\right)$. Dengan cara yang sama dapat diperoleh $\underline{\lim }_{x \rightarrow x_{0}} f(x)=f\left(x_{0}\right)$. Dengan kata lain, fungsi $f$ semikontinu atas dan semikontinu bawah pada $E$.

(Syarat cukup). Diketahui fungsi $f$ semikontinu atas dan semikontinu bawah pada $E$, maka fungsi $f$ semikontinu atas dan semikontinu bawah di $x_{0}$. Oleh karena itu diperoleh

$$
\varlimsup_{x \rightarrow x_{0}} f(x)=\underline{\lim }_{x \rightarrow x_{0}} f(x)=f\left(x_{0}\right) \text {. }
$$

Berdasarkan Teorema 1.6 diperoleh $f\left(x_{0}\right)=\lim _{x \rightarrow x_{0}} f(x)$. Dengan kata lain, fungsi $f$ kontinu di $x_{0}$. Jadi terbukti fungsi $f$ kontinu pada $E$.

Selanjutnya akan dibahas sifat-sifat fungsi semikontinu yang sangat diperlukan dalam pembahasan pada bab-bab selanjutnya.

Lemma 2.4. Diberikan fungsi fungsi $f$ dan $g$ yang didefinisikan pada $E$, dengan $f$ fungsi semikontinu bawah pada $E$ dan $g$ fungsi semikontinu atas pada $E$.

1) Jika $-\infty<c<0$ maka $c f$ fungsi semikontinu atas pada $E$ dan $c g$ fungsi semikontinu bawah pada $E$. 
2) Jika $0 \leq c<\infty$ maka $c f$ fungsi semikontinu bawah pada $E$ dan $c g$ fungsi semikontinu atas pada E.

Bukti: Diambil sembarang $x_{0} \in E$. Apabila $x_{0} \in E \backslash E^{\prime}$ maka berdasarkan Lemma 1.3 pernyataan (1) dan (2) berlaku. Selanjutnya, ditinjau untuk $x_{0} \in E \cap E^{\prime}$.

1) Diambil sembarang bilangan $c$, dengan $-\infty<c<0$. Diketahui fungsi $f$ semikontinu bawah pada

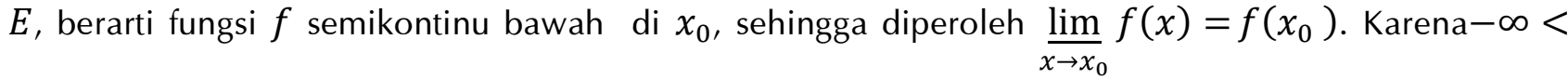
$c<0$ maka diperoleh

$$
c f\left(x_{0}\right)=c \underline{\lim }_{x \rightarrow x_{0}} f(x)=\varlimsup_{x \rightarrow x_{0}} c f(x)
$$

Dengan kata lain, $c f$ fungsi semikontinu atas di $x_{0}$. Oleh karena itu, $c f$ fungsi semikontinu atas pada $E$. Disisi lain, diketahui $g$ fungsi semikontinu atas pada $E$, berarti $g$ fungsi semikontinu atas di $x_{0}$. Sehingga diperoleh

$$
\varlimsup_{x \rightarrow x_{0}} g(x)=g\left(x_{0}\right) .
$$

Karena $-\infty<c<0$, maka diperoleh

$$
\underline{\lim }_{x \rightarrow x_{0}} c g(x)=c \varlimsup_{x \rightarrow x_{0}} g(x)=c g\left(x_{0}\right) . \mathrm{e}
$$

Dengan kata lain $c g$ fungsi semikontinu bawah di $x_{0}$. Oleh karena itu, $c g$ fungsi semikontinu bawah pada $E$.

2) Diambil sembarang bilangan $c$, dengan $0 \leq c<\infty$. Diketahui $f$ fungsi semikontinu bawah pada $E$, berarti $f$ fungsi semikontinu bawah di $x_{0}$. Berdasarkan pernyataan 1 , diperoleh $-c f$ fungsi semikontinu atas di $x_{0}$, sehingga diperoleh $(-1)(-c f)$ fungsi semikontinu bawah di $x_{0}$. Dengan kata lain, $c f$ fungsi semikontinu bawah di $x_{0}$. Oleh karena itu, $c f$ fungsi semikontinu bawah pada $E$. Disisi lain, diketahui $g$ fungsi semikontinu atas pada $E$, berarti $g$ fungsi semikontinu atas di $x_{0}$. Oleh karena itu, $-c g$ fungsi semikontinu bawah di $x_{0}$, sehingga $(-1)(-c g)$ fungsi semikontinu atas di $x_{0}$. Dengan kata lain, $c g$ fungsi semikontinu atas di $x_{0}$. Jadi, $c g$ fungsi semikontinu atas pada $E$.

Teorema 2.5. Diberikan fungsi $f$ yang didefinisikan pada $E$ dan $x_{0} \in E$.

1) Fungsi $f$ semikontinu bawah di $x_{0}$ jika dan hanya jika untuk setiap bilangan $h$, dengan $h<f\left(x_{0}\right)$ terdapat bilangan $\varepsilon>0$ sehingga $f(x)>h$ untuk setiap $x \in N_{\varepsilon}\left(x_{0}\right) \cap E$.

2) Fungsi $f$ semikontinu atas di $x_{0}$ jika dan hanya jika untuk setiap bilangan $h$, dengan $h>f\left(x_{0}\right)$ terdapat bilangan $\varepsilon>0$ sehingga $f(x)<h$ untuk setiap $x \in N_{\varepsilon}\left(x_{0}\right) \cap E$.

Bukti: Cukup dibuktikan bagian (1), untuk bagian (2) bukti dilakukan dengan cara serupa. Diambil sembarang $x_{0} \in E$. Untuk $x_{0} \in E \backslash E^{\prime}$ diambil sembarang bilangan $h$, dengan $h\left\langle f\left(x_{0}\right)\right.$. Terdapat $\left.\varepsilon\right\rangle$ 0 sehingga $N_{\varepsilon}\left(x_{0}\right) \cap E=\left\{x_{0}\right\}$. Akibatnya diperoleh $f(x)>h$ untuk setiap $x \in N_{\varepsilon}\left(x_{0}\right) \cap E$. Sebaliknya, berdasarkan Definisi 2.2 jelas fungsi $f$ semikontinu bawah di $x_{0}$. Selanjutnya ditinjau untuk $x_{0} \in E \cap E^{\prime}$.

(Syarat perlu). Diambil sembarang bilangan $h$, dengan $h<f\left(x_{0}\right)$. Karena fungsi $f$ semikontinu bawah

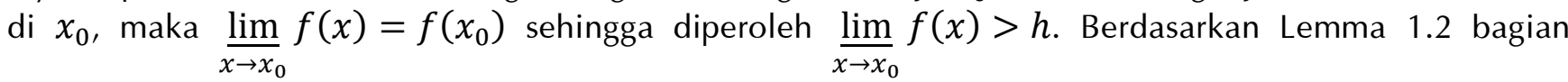
(1), maka terdapat $\varepsilon>0$ sehingga $m_{\varepsilon}\left(f, x_{0}\right)>h$. Oleh karena itu, diperoleh 


$$
m_{\varepsilon}\left(f, x_{0}\right)=\inf \left\{f(x): x \in N_{\varepsilon}\left(x_{0}\right) \cap E\right\}>h .
$$

Akibatnya $f(x)>h$, untuk setiap $x \in N_{\varepsilon}\left(x_{0}\right) \cap E$.

(Syarat cukup). Diberikan sembarang bilangan $h$, dengan $f\left(x_{0}\right)>h$. Berdasarkan hipotesa, ada bilangan $\varepsilon>0$ sehingga $f(x)>h$, untuk setiap $x \in N_{\varepsilon}\left(x_{0}\right) \cap E$. Oleh karena itu, berlaku

$$
m_{\varepsilon}\left(f, x_{0}\right)=\inf \left\{f(x): x \in N_{\varepsilon}\left(x_{0}\right) \cap E\right\} \geq h .
$$

Akibatnya diperoleh

$$
\underline{\lim }_{x \rightarrow x_{0}} f(x)=\sup \left\{m_{\varepsilon}\left(f, x_{0}\right): \varepsilon>0\right\} \geq m_{\varepsilon}\left(f, x_{0}\right) \geq h
$$

Karena $\underline{\lim }_{x \rightarrow x_{0}} f(x) \geq h$, untuk setiap $h<f\left(x_{0}\right)$, maka $\underset{\lim _{x \rightarrow x_{0}}}{\lim } f(x) \geq f\left(x_{0}\right)$. Sebaliknya, karena untuk sembarang $\varepsilon>0$ berlaku

$$
f\left(x_{0}\right) \geq m_{\varepsilon}\left(f, x_{0}\right)=\inf \left\{f(x): x \in N_{\varepsilon}\left(x_{0}\right) \cap E\right\},
$$

maka diperoleh $f\left(x_{0}\right) \geq \sup \left\{m_{\varepsilon}\left(f, x_{0}\right): \varepsilon>0\right\}=\underline{\lim }_{x \rightarrow x_{0}} f(x)$. Jadi terbukti $\underline{\lim }_{x \rightarrow x_{0}} f(x)=f\left(x_{0}\right)$. Dengan kata lain fungsi $f$ semikontinu bawah di $x_{0}$.

Dengan memanfaatkan teorema sebelumnya, berikut ini diberikan syarat perlu dan cukup untuk fungsi semikontinu bawah dan semikontinu atas.

Teorema 2.6. Diberikan fungsi $f$ yang didefinisikan pada $E$.

1) Fungsi $f$ semikontinu bawah pada $E$ jika dan hanya jika untuk setiap $h \in \boldsymbol{R}\{x \in E: f(x)>h\}$ merupakan himpunan terbuka.

2) Fungsi $f$ semikontinu atas pada $E$ jika dan hanya jika untuk setiap $l \in \boldsymbol{R}\{x \in E: f(x)<l\}$ merupakan himpunan terbuka.

Bukti: Cukup dibuktikan bagian (1), untuk bagian (2) bukti dilakukan dengan cara serupa.

(Syarat perlu). Diambil sembarang $h \in \boldsymbol{R}$. Namakan $A=\{x \in E: f(x)>h\}$, akan dibuktikan $A$ terbuka. Diambil sembarang $c$ titik limit $A^{c}$ dan $\alpha \in \boldsymbol{R}$ dengan $\alpha<f(c)$. Berdasarkan Teorema 2.5 bagian (1), terdapat $\varepsilon>0$ sehingga berlaku $f(x)>\alpha$ untuk setiap $x \in N_{\varepsilon}(c) \cap E$. Selanjutnya, karena $c$ titik limit $A^{c}$, maka terdapat $z \in N_{\varepsilon}(c) \cap A^{c} \backslash\{c\}$ sehingga $\alpha<f(z) \leq h$. Karena $h>\alpha$ untuk setiap $\alpha<$ $f(c)$, maka diperoleh $f(c) \leq h$. Dengan kata lain, $c \in A^{c}$. Oleh karena itu $A^{c}$ tertutup. Jadi terbukti $A$ terbuka.

(Syarat cukup). Diambil sembarang $c \in E$ dan bilangan $h$, dengan $h<f(c)$. Namakan $A=$ $\{x \in E: f(x)>h\}$. Berdasarkan hipotesa himpunan $A^{c}$ tertutup. Karena $A^{c}$ tertutup dan tidak memuat titik $c$, berarti $c$ bukan titik limit $A^{c}$. Oleh karena itu, terdapat bilangan $\delta>0$ sehingga $f(x)>h$ untuk setiap $x \in N_{\delta}(c) \cap E$. Berdasarkan Teorema 2.5 diperoleh fungsi $f$ semikontinu bawah di $c$. Karena berlaku untuk sembarang $c \in E$ maka fungsi $f$ semikontinu bawah pada $E$.

Teorema 2.7. Diberikan fungsi $f$ yang terbatas pada ruang metrik $(E, d)$. Fungsi $f$ semikontinu bawah pada $E$ jika dan hanya jika terdapat barisan naik monoton fungsi fungsi kontinu $\left\{f_{n}\right\}$ pada $E$ sehingga $\left\{f_{n}\right\}$ konvergen titik demi titik ke $f$ pada $E$. 
Bukti: (Syarat perlu). Untuk setiap $n \in \boldsymbol{N}$, didefinisikan $f_{n}: E \rightarrow \boldsymbol{R}$, dengan

$$
f_{n}(x)=\inf \{f(t)+n d(x, t): t \in E\} .
$$

Akan ditunjukkan $\left\{f_{n}\right\}$ naik monoton. Untuk setiap $n \in \boldsymbol{N}$, berlaku

$$
f(t)+n d(x, t) \leq f(t)+(n+1) d(x, t), \text { untuk setiap } x, t \in E .
$$

Oleh karena itu, diperoleh $f_{n}(x) \leq f_{n+1}(x)$, untuk setiap $n \in \boldsymbol{N}$. Dengan kata lain barisan $\left\{f_{n}\right\}$ naik monoton.

Selanjutnya akan dibuktikan untuk setiap $n \in \boldsymbol{N}, f_{n}$ kontinu pada $E$. Diambil sembarang $x, y \in E$, diperoleh

$$
\begin{aligned}
& f_{n}(x)=\inf \{f(t)+n d(x, t): t \in E\} \\
& \quad \leq \inf \{f(t)+n d(y, t)+n d(x, y): t \in E\} \\
& \quad=\inf \{f(t)+n d(y, t): t \in E\}+n d(x, y) \\
& \quad=f_{n}(y)+n d(x, y) .
\end{aligned}
$$

Dengan kata lain, diperoleh

$$
f_{n}(x)-f_{n}(y) \leq n d(x, y)
$$

Dengan cara yang sama, diperoleh

$$
f_{n}(y)-f_{n}(x) \leq n d(x, y)
$$

Oleh karena itu, berdasarkan (2) dan (3) diperoleh

$$
\left|f_{n}(y)-f_{n}(x)\right| \leq n d(x, y)
$$

Selanjutnya, diberikan $\varepsilon>0$ sembarang, dipilih $\delta=\frac{\varepsilon}{n+1}$ sehingga untuk setiap $x, y \in E$ dengan $d(x, y)<\delta$, berlaku $\left|f_{n}(y)-f_{n}(x)\right| \leq n d(x, y)<n \delta<\varepsilon$.

Dengan kata lain, terbukti bahwa $f_{n}$ kontinu pada $E$.

Selanjutnya akan dibuktikan $\lim _{n \rightarrow \infty} f_{n}(x)=f(x)$, untuk setiap $x \in E$. Karena fungsi $f$ terbatas pada $E$ maka $f$ terbatas kebawah pada $E$. Oleh karena itu terdapat bilangan $M$, sehingga $M \leq f(x)$ untuk setiap $x \in E$. Diambil sembarang $x_{0} \in E$, maka untuk setiap $n \in \boldsymbol{N}$ berlaku

$$
f_{n}\left(x_{0}\right)=\inf \left\{f(t)+n d\left(x_{0}, t\right): t \in E\right\} .
$$

Oleh karena itu, diperoleh $f_{n}\left(x_{0}\right) \leq f\left(x_{0}\right)+n d\left(x_{0}, x_{0}\right)=f\left(x_{0}\right)$. Akibatnya,

$$
\lim _{n \rightarrow \infty} f_{n}\left(x_{0}\right) \leq f\left(x_{0}\right) .
$$

Sebaliknya, diambil sembarang bilangan $h$, dengan $h<f\left(x_{0}\right)$. Berdasarkan Teorema 2.5, terdapat bilangan $\varepsilon>0$ sehingga $f(x)>h$, untuk setiap $x \in N_{\varepsilon}\left(x_{0}\right) \cap E$. Karena $h, M, \varepsilon \in \boldsymbol{R}$ maka $\frac{h-M}{\varepsilon} \in \boldsymbol{R}$, menurut Archimedes terdapat $n_{0} \in \boldsymbol{N}$ sehingga $n_{0}>\frac{h-M}{\varepsilon}$. Dengan kata lain, terdapat $n_{0} \in \boldsymbol{N}$ sehingga $M+\varepsilon n_{0}>h$. Untuk setiap bilangan $n>n_{0}$, apabila $t \in N_{\varepsilon}\left(x_{0}\right) \cap E$, maka berlaku 


$$
\begin{aligned}
f_{n}\left(x_{0}\right) & =\inf \left\{f(t)+n d\left(x_{0}, t\right): t \in N_{\varepsilon}\left(x_{0}\right) \cap E\right\} \\
& \geq \inf \left\{f(t): t \in N_{\varepsilon}\left(x_{0}\right) \cap E\right\} \\
& \geq h .
\end{aligned}
$$

Sedangkan untuk nilai-nilai $t$ yang lain,

$$
\begin{aligned}
f_{n}\left(x_{0}\right) & =\inf \left\{f(t)+n d\left(x_{0}, t\right): t \in E \backslash N_{\varepsilon}\left(x_{0}\right)\right\} \\
& \geq \inf \left\{M+n \varepsilon: t \in E \backslash N_{\varepsilon}\left(x_{0}\right)\right\} \\
& =M+n \varepsilon>M+\varepsilon n_{0}>h .
\end{aligned}
$$

Dengan demikian, untuk setiap $n>n_{0}$, karena $f_{n}\left(x_{0}\right) \geq h$ untuk setiap $h<f\left(x_{0}\right)$ maka diperoleh $f_{n}\left(x_{0}\right) \geq f\left(x_{0}\right)$. Oleh karena itu, diperoleh

$$
\lim _{n \rightarrow \infty} f_{n}\left(x_{0}\right) \geq f\left(x_{0}\right) .
$$

Berdasarkan (4) dan (5) diperoleh $\lim _{n \rightarrow \infty} f_{n}\left(x_{0}\right)=f\left(x_{0}\right)$.

(Syarat cukup). Diambil sembarang $\alpha \in \boldsymbol{R}$. Akan dibuktikan bahwa himpunan $\{x \in E: f(x)>\alpha\}$ terbuka. Akan ditunjukkan terlebih dahulu bahwa

$$
\{x \in E: f(x)>\alpha\}=\bigcup_{n=1}^{\infty}\left\{x \in E: f_{n}(x)>\alpha\right\} .
$$

Diambil sembarang $x \in\{x \in E: f(x)>\alpha\}$, maka berlaku $f(x)>\alpha$. Andaikan $f_{n}(x) \leq \alpha$, untuk setiap $n \in N$, maka berlaku, $f_{n}(x) \leq \alpha<f(x)$. Karena $f(x)>\alpha$ maka $f(x)-\alpha>0$. Oleh karena itu, diambil $\varepsilon=\frac{1}{2}(f(x)-\alpha)>0$. Untuk setiap $n \in N$, diperoleh

$$
\left|f_{n}(x)-f(x)\right| \geq|f(x)-\alpha|=f(x)-\alpha>\frac{1}{2}(f(x)-\alpha)=\varepsilon .
$$

Kontradiksi dengan $\left\{f_{n}\right\}$ konvergen titik demi titik ke $f$. Jadi $f_{n}(x)>\alpha$, untuk suatu $n \in \boldsymbol{N}$. Dengan kata lain, terbukti $x \in \bigcup_{n=1}^{\infty}\left\{x \in E: f_{n}(x)>\alpha\right\}$.

Sebaliknya, diambil sembarang $x \in \bigcup_{n=1}^{\infty}\left\{x \in E: f_{n}(x)>\alpha\right\}$, maka terdapat $N \in N$ sehingga $f_{N}(x)>$ $\alpha$. Andaikan $f(x) \leq \alpha$, maka diperoleh

$$
f_{N}(x)>\alpha \geq f(x)
$$

Karena barisan $\left\{f_{n}\right\}$ naik monoton, maka $f_{m} \geq f_{N}$, untuk setiap $m>N$. Diambil $\varepsilon=$ $\frac{1}{2}\left(f_{N}(x)-f(x)\right)>0$. Karena $f(x)<f_{N}(x) \leq f_{m}(x)$, untuk setiap $m>N$, maka diperoleh

$$
\left|f_{m}(x)-f(x)\right| \geq\left|f_{N}(x)-f(x)\right| \geq \varepsilon
$$

Kontradiksi dengan $\left\{f_{n}\right\}$ konvergen titik demi titik ke $f$. Jadi $f(x)>\alpha$. Oleh karena itu diperoleh $\{x \in E: f(x)>\alpha\}=\bigcup_{n=1}^{\infty}\left\{x \in E: f_{n}(x)>\alpha\right\}$. Karena himpunan $\left\{x \in E: f_{n}(x)>\alpha\right\}$ terbuka, maka $\cup_{n=1}^{\infty}\left\{x \in E: f_{n}(x)>\alpha\right\}$ terbuka. Akibatnya himpunan $\{x \in E: f(x)>\alpha\}$ terbuka. Berdasarkan Teorema 2.2.15 maka terbukti fungsi $f$ semikontinu bawah pada $E$.

Sebelum membahas teorema berikutnya, akan didefinisikan terlebih dahulu limit atas dan limit bawah barisan bilangan real. Diberikan barisan bilangan real $\left\{x_{n}\right\}$. Limit atas (upper limit) barisan $\left\{x_{n}\right\}$ dituliskan dengan $\varlimsup_{n \rightarrow \infty} x_{n}$ dan didefinisikan 


$$
\varlimsup_{n \rightarrow \infty} x_{n}=\inf _{n} \sup \left\{x_{k}: k \geq n\right\}
$$

Sedangkan, limit bawah (lower limit) barisan $\left\{x_{n}\right\}$ dituliskan dengan $\underset{n \rightarrow \infty}{\lim } x_{n}$ dan didefinisikan

$$
\varliminf_{n \rightarrow \infty} x_{n}=\sup _{n} \inf \left\{x_{k}: k \geq n\right\}
$$

Teorema 2.8. Diberikan fungsi $f$ yang didefinisikan pada $E$.

1) Fungsi $f$ semikontinu bawah pada $E$ jika dan hanya jika untuk setiap $x \in E$ dan setiap barisan $\left\{x_{n}\right\}$ di $E$ yang konvergen ke $x$ berakibat

$$
\varliminf_{n \rightarrow \infty} f\left(x_{n}\right) \geq f(x) \text {. }
$$

2) Fungsi $f$ semikontinu atas pada $E$ jika dan hanya jika untuk setiap $x \in E$ dan setiap barisan $\left\{x_{n}\right\}$ di $E$ yang konvergen ke $x$ berakibat

$$
\varlimsup_{n \rightarrow \infty} f\left(x_{n}\right) \leq f(x) \text {. }
$$

Bukti: Cukup dibuktikan bagian (1), untuk bagian (2) bukti dilakukan dengan cara yang sama. (Syarat perlu). Diambil sembarang $x \in E$ dan barisan $\left\{x_{n}\right\}$ di $E$ dengan $\left\{x_{n}\right\}$ konvergen ke $x$. Akan dibuktikan $\varliminf_{n \rightarrow \infty} f\left(x_{n}\right) \geq f(x)$. Diambil sembarang bilangan $b$ sehingga $f(x)>b$. Dibentuk $V=\{y: f(y)>b\}$. Karena fungsi $f$ semikontinu bawah, maka berdasarkan Teorema 2.6 bagian (1) diperoleh $V$ merupakan himpunan terbuka dan jelas $x \in V$. Selanjutnya, karena $x \in V$, dengan $V$ terbuka dan barisan $\left\{x_{n}\right\}$ konvergen ke $x$, maka terdapat $n_{0} \in \boldsymbol{N}$ sehingga untuk setiap $n \geq n_{0}$ diperoleh $x_{n} \in V$. Oleh karena itu, $f\left(x_{n}\right)>b$. Akibatnya, diperoleh $\underline{\lim }_{n \rightarrow \infty} f\left(x_{n}\right) \geq b$. Karena $\underline{\lim }_{n \rightarrow \infty} f\left(x_{n}\right) \geq b$ untuk sembarang $b<f(x)$, maka diperoleh $\underline{\lim }_{n \rightarrow \infty} f\left(x_{n}\right) \geq f(x)$.

(Syarat cukup). Diambil sembarang $a \in \boldsymbol{R}$. Namakan $W=\{x: f(x)>a\}$, akan dibuktikan $W$ terbuka. Diambil sebarang barisan $c$ titik limit $W^{c}$, maka terdapat barisan $\left\{x_{n}\right\} \subseteq W^{c}$ dengan $\left\{x_{n}\right\}$ konvergen ke $c$. Oleh karena itu, diperoleh $f\left(x_{n}\right) \leq a$ untuk setiap $n$. Akibatnya, $\underline{\lim }_{n \rightarrow \infty} f\left(x_{n}\right) \leq a$. Selanjutnya, berdasarkan hipotesa, diperoleh $f(c) \leq \lim _{n \rightarrow \infty} f\left(x_{n}\right) \leq a$. Dengan demikian diperoleh $f(c) \leq a$, yang berarti $\quad c \in W^{c}$. Dengan kata lain $W$ terbuka. Jadi terbukti $f$ fungsi semikontinu bawah pada $E$.

Teorema 2.9. Diberikan fungsi-fungsi $f$ dan $g$ yang didefinisikan pada $E$.

1) Jika fungsi-fungsi $f$ dan $g$ semikontinu atas pada $E$ maka $f+g$ juga fungsi semikontinu atas pada E.

2) Jika fungsi $f$ dan $g$ semikontinu bawah pada $E$ maka $f+g$ juga semikontinu bawah pada $E$.

Bukti: Cukup dibuktikan bagian (1), untuk bagian (2) bukti dilakukan dengan cara yang sama. Diambil sembarang $x_{0} \in E$. Diketahui fungsi-fungsi $f$ dan $g$ semikontinu atas pada $E$, maka fungsi-fungsi $f$ dan $g$ semikontinu atas di $x_{0}$. Sehingga berlaku $f\left(x_{0}\right)=\varlimsup_{x \rightarrow x_{0}} f(x)$ dan $g\left(x_{0}\right)=\varlimsup_{x \rightarrow x_{0}} g(x)$. Oleh karena itu, diperoleh

$$
f\left(x_{0}\right)+g\left(x_{0}\right)=\varlimsup_{x \rightarrow x_{0}} f(x)+\varlimsup_{x \rightarrow x_{0}} g(x) \geq \varlimsup_{x \rightarrow x_{0}}(f+g)(x)
$$

Sebaliknya, karena untuk sembarang $\varepsilon>0$ berlaku

$$
M_{\varepsilon}\left((f+g), x_{0}\right)=\sup \left\{(f+g)(x): x \in N_{\varepsilon}\left(x_{0}\right) \cap E\right\} \geq f\left(x_{0}\right)+g\left(x_{0}\right),
$$


maka, diperoleh

$$
\varlimsup_{x \rightarrow x_{0}}(f+g)(x)=\inf \left\{M_{\varepsilon}\left((f+g), x_{0}\right): \varepsilon>0\right\} \geq f\left(x_{0}\right)+g\left(x_{0}\right) .
$$

Dengan demikian diperoleh $f\left(x_{0}\right)+g\left(x_{0}\right)=\varlimsup_{x \rightarrow x_{0}}(f+g)(x)$. Dengan kata lain, terbukti $f+g$ fungsi semikontinu atas pada $E$.

Teorema 2.20. Diberikan fungsi-fungsi $f$ dan $g$ yang didefinisikan pada $E$. Jika fungsi-fungsi $f$ dan $g$ nonnegatif dan semikontinu bawah pada $E$ maka $f . g$ juga fungsi semikontinu bawah pada $E$.

Selanjutnya akan diberikan definisi fungsi envelope semikontinu atas dan fungsi envelope semikontinu bawah dengan menggunakan konsep limit atas dan limit bawah seperti yang telah dibahas sebelumnya.

Definisi 2.21. Diberikan fungsi $f$ yang didefinisikan pada $E$.

1) Fungsi envelope semikontinu atas dari $f$ (upper semicontinuous envelope) ditulis dengan $U f$, dan didefinisikan

$U f(x)=\varlimsup_{y \rightarrow x} f(y)$,

untuk setiap $x \in E$.

2) Fungsi envelope semikontinu bawah dari $f$ (lower semicontinuous envelope) ditulis dengan $L f$, dan didefinisikan

$L f(x)=\lim _{y \rightarrow x} f(y)$,

untuk setiap $x \in E$.

Selanjutnya akan dibahas beberapa sifat fungsi envelope semikontinu atas dan semikontinu bawah, yang akan digunakan pada bab-bab berikutnya.

Lemma 2.22. Diberikan fungsi-fungsi $f$ dan $g$ yang didefinisikan pada $E$, maka berlaku

1) $f \leq U f$

2) $L f \leq f$

3) Jika $f \leq g$ maka $U f \leq U g$.

4) $U(f+g) \leq U f+U g$.

5) $U f=f$ jika dan hanya jika fungsi $f$ semikontinu atas pada $E$.

Lemma 2.23. Diberikan fungsi-fungsi $f$ dan $g$ yang didefinisikan pada $E$, maka berlaku

$$
U(f-U g)=U(U f-U g) \leq U(f-g) .
$$

Bukti: Berdasarkan Teorema 1.9 bagian (1), diperoleh $U f-U g \leq U(f-g)$. Oleh karena itu, diperoleh

$$
U(U f-U g) \leq U(f-g) .
$$

Selanjutnya, karena $f-U g \leq U f-U g$, maka diperoleh

$$
U(f-U g) \leq U(U f-U g)
$$

Disisi lain, karena $U f-U g=U f-U(U g) \leq U(f-U g)$, maka diperoleh

$$
U(U f-U g) \leq U(f-U g) .
$$


Berdasarkan (6), (7), dan (8) terbukti bahwa

$$
U(f-U g)=U(U f-U g) \leq U(f-g)
$$

Lemma 2.24. Diberikan fungsi $f$ yang didefinisikan pada $E$. Jika fungsi $f$ non negatif dan terbatas pada $E$ maka berlaku $\|U f\|_{\infty}=\|f\|_{\infty}$.

Bukti: Diambil sebarang $x \in E$. Karena $U f(x) \geq f(x)$ dan fungsi $f$ non negatif maka berlaku

Oleh karena itu, diperoleh

$$
|U f(x)| \geq|f(x)|
$$

$$
\|U f\|_{\infty} \geq\|f\|_{\infty}
$$

Sebaliknya, diambil $\varepsilon>0$ sembarang. Karena $N_{\varepsilon}(x) \cap E \subseteq E$, maka berlaku

$$
M_{\varepsilon}(f, x)=\sup \left\{f(y): y \in N_{\varepsilon}(x) \cap E\right\} \leq \sup \{f(y): y \in E\} .
$$

Oleh karena itu, diperoleh

$$
|U f(x)| \leq\|f\|_{\infty}
$$

Akibatnya diperoleh $\|U f\|_{\infty} \leq\|f\|_{\infty}$. Dengan demikian terbukti bahwa

$$
\|U f\|_{\infty}=\|f\|_{\infty}
$$

\section{Kesimpulan}

Pendefinisian fungsi semikontinu menggunakan konsep limit atas dan limit bawah. Pembuktian sifatsifat fungsi semikontinu banyak memanfaatkan sifat limit atas dan limit bawah, oleh karena itu penting terlebih dahulu memahami konsep dan sifat-sifat limit atas dan limit bawah.

\section{Referensi}

[1] Ash, R.B., 2007, Real Variables with Basic Metric Space Topology, Department of Mathematics University of Illionis at Urbana-Champaign.

[2] Dugundji, J., 1966, Topology, Allyn and Bacon, Inc., Boston.

[3] Farmaki, V., 1996, On Baire-1/4 Functions, Trans. Amer. Math. Soc, 348, 10.

[4] Gordon, R. A., 1994, The Integral of Lebesgue, Denjoy, Perron and Henstock, American Mathematical Society, USA.

[5] Haydon, R., Odell, E. dan Rosenthal, H.P., 1991, On Certain Classes of Baire-1 Functions with Applications to Banach Space Theory, Lecture Notes in Math., 1470, Springer, New York.

[6] Kreyszig, E., 1978, Introductory Functional Analysis with Applications, John Wiley and Sons, Inc., Canada

[7] McShane, E.J., 1944, Integration, Princeton University Press, Princeton.

[8] Rosenthal, H.P., 1994, A Characterization of Banach Spaces Containing C0, J. Amer. Math. Soc, 7, 3, 707-748.

[9] Rosenthal, H.P., 1994, Differences of Bounded Semi-Continuous Functions I, http://www.arxiv.org/abs/math/9406217, 20 Juni 1994, diakses pada tanggal 27 Agustus 2009.

[10] Royden, H.L., 1989, Real Analysis, Macmillan Publishing Company, New York. 